\section{Epidemiology of Yellow Fever}

URBAN outbreaks of yellow fever are brought to an end either by the eradication of the mosquito vector, Aëdes (Stegomyia) aegypti, or by the immunization of a high percentage of the human population. Rural outbreaks are less easily controlled, for in yellow fever areas both in Africa and South America 20-25 per cent of wild monkeys are found to possess immune bodies to yellow fever; in South America, in addition, the so-called jungle yellow fever is transmitted by non-domestic forest-living mosquitoes. Although mosquitoes once capable of transmitting yellow fever by bite appear to remain infective, their life span is short and they are unable to transfer the virus to other mosquitoes either by contact or hereditarily through the egg. If the mosquito-man and mosquito-monkey cycle of transmission represents the complete epidemiological picture of yellow fever, it is not easy to account for the persistence of infection in rural areas during dry seasons when adult mosquitoes are either absent or are present only in very small numbers. It has therefore been suggested that other arthropods may possibly harbour the yellow fever virus, such arthropod vectors either having a longer life than ædine mosquitoes or being able to transmit the virus hereditarily. So far, no biting arthropods other than mosquitoes have been found of importance in the epidemiology of yellow fever.

Two recent observations, however, suggest that it may be necessary to consider non-biting arthropods as possible vectors of yellow fever. In the first place, it has been found possible to infect monkeys with yellow fever by the alimentary canal. When yellow fever virus was introduced by means of a soft catheter into the stomachs of Indian monkeys (Macaca mulatta) and African monkeys (Cercopithecus aethiops), the virus passed into the blood stream and, in the case of Indian monkeys, caused fatal infection. Similar attempts to infect by the alimentary tract failed in man, dog, rabbit, guinea pig, rat, mouse, hen and pigeon. In the second place, it has been shown that when yellow fever virus is injected into the abdomen of the cockroach, Blatella germanica, kept at $19^{\circ} \mathrm{C}$., the virus retains its activity certainly for fifteen days. Though it is not suggested that the cockroach necessarily plays any part in the epidemiology of yellow fever, it has long been known that both African and South American monkeys supplement their mainly vegetarian diet by grubs and insects. Precise data as to the insects eaten are, however, lacking; but in view of the observations described, it would be of considerable interest to determine what animal foods are actually eaten under natural conditions by monkeys in the yellow fever areas of Africa and South America.

\section{G. M. Findlay.}

F. O. MacCallum.

Wellcome Bureau of Scientific Research, London, N.W.1. Jan. 2.

\section{Kinetochore or Centromere?}

Few questions in cytological terminology can have caused more disagreement and disorder than that of the name to be applied to the portion of the chromosome which determines its movements on the spindle. The names given to this body have been many, and Dr. Schrader's appeal ${ }^{1}$ for the general adoption of one term, with the abandonment of all others, must be received sympathetically by cytologists and geneticists. He proposes, however, the adoption of the term 'kinetochore', saying that it has been employed by Sharp in his text-book ${ }^{2}$. Sharp certainly recommends the term in a footnote, but he has not, so far as I can observe, carried out his own recommendation. Schrader's alternative proposal is to introduce yet another new term.

Where there exist two or more names for an organ, it is generally found that one of them gradually ousts the rest and becomes established as the accepted term. This process of selection may be seen at work in the special case to which Schrader directs attention. Of the innumerable names which have been proposed, only two main forms appear commonly in present-day literature. One of these, the old term 'spindle fibre attachment', with its variants, is clumsy, somewhat misleading and highly inadaptable. Doubtless it will be discarded in time. The other, Darlington's 'centromere', implies a visible particle instead of a dubious relationship, and has many advantages, being intelligible, pronounceable and adaptable. The adjectives 'acentric', 'dicentric', etc., which are so easily derived from the name 'centromere' add materially to its value. There can be little doubt that it is the best term in use to-day. Dr. Schrader would appear to agree with this statement, as of all the terms he wishes to discard, 'centromere' is the only one for the rejection of which he gives detailed reasons. These are two : (1) that the word has been used earlier in a different connexion by Waldeyer, and (2) that 'centromere' is likely to be confused with 'centrosome', 'centriole', etc.

Now Wilson's glossary, so long ago as $1925^{3}$, gives Waldeyer's usage as obsolete, so the first objection can carry little weight. Secondly, the confusion between 'centromere', 'centrosome', etc., is likely to be no greater than that between 'chromomere', 'chromosome', 'chromatin', 'chromatid' and 'chromonema', all of which are in common use to-day and do not, so far as I am aware, cause any serious difficulty. The lack of weight of Schrader's objections is further shown by the growing popularity of the term 'centromere'. Since its inception in 1936, it has come to be used not only by the English authors admitted by Schrader, but also by many others. In recent papers, Muller ${ }^{4}$, $\mathrm{Sax}^{5}$, Stone ${ }^{6}$, Kostoff 7 , Geitler ${ }^{8}$, Levan ${ }^{9}$, Satô ${ }^{10}$, Klingstedt ${ }^{11}$, Husted ${ }^{12}$, Matthey ${ }^{13}$ and Parthasarathy ${ }^{14}$ all employ this name, some for cytological and others for genetical purposes.

Thus it appears that Darlington's term is doing all that Schrader desires. Its use is growing rapidly, and we may look forward with reasonable confidence to the time when, by its own merits, it will have replaced the ten or more other names. To introduce 'kinetochore', or some entirely new word, would be to confound further the present confusion and to delay the achievement of the unanimity which Schrader so reasonably advocates.

John Innes Horticultural Institution, K. MATHER. Merton, London. Jan. 28. "Schrader, F., NATCRE, 143, 122 (1939).
" Sharp, L. W., "Introduction to Cytology" (3rd ed.) (New York : McGraw-Hill, 1934).

${ }^{3}$ Wilson, E. B., "The Cell in Development and Heredity" (3rd ed.) (New York: Macmillan, 1925).

4 Muller, H. J., Collecting Net, 13, 181-198 (1938)

5 Sax, K., Genetics, 23, 494-516 (1938).

- Stone, W. S., and Griffin, A. B., Genetics, 23, 173 (1938).

" Kostoff, D., 'J. Genet., 37, 129-208 (1938)

${ }^{8}$ Geitler, L. v., Z. indukt.'Abstamm. u. Vererb. Lehre, 75, 161-190 (1938).

- Levan, A., Hereditas, 25, 9-26 (1939).

10 Sat , D., Cytologia, Fuj. Jub. Vol., 80-95 (1937).

${ }^{11}$ Klingstedt, H., Memor. Soc. Fauna Flor. fenn., 12, 194-209 (1937).

12 Husted, L., J'. Genet., 34, 329-338 (1937).

14 Parthasarathy, N., J. Genet., 37, 1-40 (1938). 